\title{
Bacteriology of community acquired pneumonia in adult patients at Felege Hiwot Referral Hospital, Northwest Ethiopia: a cross-sectional study
}

Dinbere Temesgen ${ }^{1}$, Fetlewok Bereded ${ }^{2}$, Awoke Derbie $^{2,3^{*}}$ (1) and Fantahun Biadglegne ${ }^{2}$

\begin{abstract}
Background: Community acquired pneumonia (CAP) is reported as a common cause of lower respiratory tract infection worldwide. Bacterial pathogens and antimicrobial resistance (AMR) associated with this infection varied between geographical regions. Knowledge of the pathogens in a given area and their up-to-date AMR profile is essential for optimal management of patients. This study was aimed at assessing the type of bacterial isolates and their AMR among CAP adult patients at the Felege Hiwot Referral Hospital (FHRH), Northwest Ethiopia.

Methods: This cross-sectional study was conducted during 1 April to 30 July 2018. Demographic related data were collected from the study participants using a structured questionnaire. Sputum samples were collected and processed to identify pathogens using the conventional culture and biochemical tests as per the standard procedures. The Kirby Bauer disk diffusion method was implemented for the AMR testing. Descriptive and multivariable analysis was conducted using SPSS version 23.

Results: Among 414 presumptively diagnosed study participants for CAP, bacterial pathogens were identified from 167 (40.3\%) participants. Among these, multidrug resistance (MDR) accounted for 127(76\%) of the isolates. The predominant isolates were Streptococcus pneumoniae at 60(35.9\%) and Klebsella pneumoniae at 30(18\%).

Overcrowded living conditions [AOR 1.579 (95\%Cl: 1.015-2.456)] and alcohol use [AOR 4.043 (95\% Cl, 2.537-6.443)]

were found statistically associated with culture positive sputum.

Conclusions: The study showed high prevalence of mono- and multi-drug resistant isolates in the study area. Therefore, regular surveillance of the type of isolates and their AMR patterns should be considered. Interventions for reducing community acquired pneumonia should be integrated with lifestyle factors related to household and alcohol use.
\end{abstract}

Keywords: Community acquired pneumonia, Multi drug resistance, Felege Hiwot Referral Hospital, Northwest Ethiopia

\footnotetext{
* Correspondence: awe.love2000@gmail.com

2Department of Medical Laboratory Sciences, College of Medicine and Health Sciences, Bahir Dar University, P.O.BOX: 1383, Bahir Dar, Ethiopia

${ }^{3}$ Center for Innovative Drug development and Therapeutics Trials for Africa

(CDT-Africa), Addis Ababa University, Addis Ababa, Ethiopia

Full list of author information is available at the end of the article
}

(c) The Author(s). 2019 Open Access This article is distributed under the terms of the Creative Commons Attribution 4.0 International License (http://creativecommons.org/licenses/by/4.0/), which permits unrestricted use, distribution, and reproduction in any medium, provided you give appropriate credit to the original author(s) and the source, provide a link to the Creative Commons license, and indicate if changes were made. The Creative Commons Public Domain Dedication waiver (http://creativecommons.org/publicdomain/zero/1.0/) applies to the data made available in this article, unless otherwise stated. 


\section{Background}

Pneumonia is reported as an acute respiratory tract infection evidenced with a clinical and/or radiological consolidation of the lungs [1]. According to Sligl and Marrie report, pneumonia developed due to the reduction of the defensive mechanisms of the lung. Pneumonia is transmitted through inhalation or aspiration of the pathogens [2]. Pneumonia, which is usually caused by bacteria, is the most common cause of hospital attendance in adults of the developing countries [1]. Van Gageldonk-Lafeber and his colleagues also showed that children and elders are highly affected by the disease [3].

Pneumonia is usually classified as community and hospital acquired or those occurred in patients with underlying damaged lung including suppurative and aspiration pneumonia [1]. According to Prina and his collegues report in 2015, community acquired pneumonia (CAP) is an infection of the lung parenchyma which is not acquired from a health care system [4]. The disease was reported as a major health problem causing morbidity and mortality worldwide [5]. In Africa, the mortality rate among adult patients varied between 6 and 15\% [6]. In South Africa, CAP was the fifth-largest killer reported at $3.9 \%$ of all deaths [7]. Previous reports showed that the prevalence of bacterial CAP in Ethiopia was varied between 42.9 and 50\% [8-10].

Studies showed that old age, smoking, alcoholism, immunosuppressive conditions, chronic obstructed pulmonary diseases (COPD) were reported as key factors for the development of the disease [1, 11, 12]. Furthermore, asthma, cardiovascular disease, chronic liver or renal disease, diabetes mellitus, overcrowded living condition, and recent upper respiratory tract infection (URTI) were reported predictors of the CAP.

In Ethiopia, the diagnosis of CAP is relied on the medical history and physical examinations of the suspected individuals. However, the clinical characteristics of CAP cannot be consistently used to establish the etiologic diagnosis with adequate sensitivity and specificity. So, appropriate bacteriological diagnosis is very important $[13,14]$. The bacterial pathogens associated with the CAP and their antimicrobial resistance pattern varied from place to place and in time [15]. Previous studies on this regard reported that Streptococcus pneumoniae (S. pneumoniae) was the most commonly isolated pathogen followed by Haemophilus influenzae (H. influenzae), Staphylococcus aureus (S. aureus), Chlamydia pneumoniae, Legionella species, and Mycoplasma pneumoniae [3, 16]. In Ethiopia, S. pneumoniae is the most frequent isolated bacteria followed by $S$. aureus [9, 17]. In these studies, most of the isolated pathogens were found to be resistant to one or more classes of antibiotics.
In developing countries including Ethiopia, treatment of CAP is made usually empirically in which the etiologic agent is rarely identified. So, identifying the most common bacterial pathogens isolated from CAP and their drug resistance profile would be valuable to reduce morbidity and mortality associated with the disease [18]. Therefore, this study was conducted to provide data on the type of bacterial pathogens and their drug resistance profile among CAP adult patients at the Felege Hiwot Referral Hospital (FHRH), Northwest Ethiopia.

\section{Materials and methods \\ Study setting, design and period}

This hospital based cross-sectional study was conducted from 1 April to 31 July, 2018 at FHRH, Northwest Ethiopia. The hospital provided specialized services to patients with its different departments. It had more than 400 beds and serving close to 10 million people in the surrounding area. The hospital is located in Bahir Dar, Amhara Regional State, Ethiopia which is about $565 \mathrm{~km}$ far from the capital city, Addis Ababa.

\section{Population, sample size and sampling technique}

A total of 414 CAP suspected adult patients were included. A single population proportion method was implemented to determine the sample size [17]. The study subjects were selected using a systematic random sampling technique. Adults, aged $\geq 18$ years that were clinically suspected for CAP and consented to participate in the study were included. However, patients who were under antibiotic treatment and had a history of hospital admission 14 days before the data collection period were excluded from the study.

\section{Operational definition}

In accordance with previous literatures $[4,9,12,19,20]$ the following terms are defined;

- Community acquired pneumonia (CAP): Pneumonia which is not acquired in a hospital or a long-term care facility.

- Multi-drug resistance (MDR): Resistance to one or more agents in three or more different classes of antimicrobials.

- Overcrowded living condition: Living with more than 10 persons at home.

- Typical symptom of pneumonia: Cough, fever, chills, fatigue, dyspnea, and pleuritic chest pain.

\section{Data collection and laboratory methods}

Data on socio-demographic characteristics and associated factors for culture positive sputum were collected using pretested structured questionnaire. 


\section{Sample collection and transport}

After the patients were instructed how to collect the sample, a total of 414 sputum samples were collected in a disposable, leak proof, sterile and wide mouthed container with tight fitting lid. The collected sputum samples were transported to Amhara Public Health Institute (APHI) microbiology laboratory, which is located close to the hospital, within $20-30 \mathrm{~min}$. Following the standard conventional sputum culture protocol, specimens were first inspected macroscopically and then microscopically for further culture analysis. Those sputum specimens with at least 25 polymorph nuclear leukocytes and less than 10 epithelial cells per low power field were processed for culture. Otherwise, the sputum sample was considered as contaminated with saliva and rejected $[17,21]$.

Process of culturing and identification of bacterial isolates Purulent portion of the sputum specimen was inoculated on MacConkay agar (MAC), Blood agar plate (BAP), and Chocolate agar plate (CAP) using a sterile swab. In order to get pure colonies, the samples were streaked in four quadrants of the plates. The inoculated MAC plates were incubated aerobically at $37^{\circ} \mathrm{C}$ for $24 \mathrm{~h}$. However, the inoculated CAP and BAP were incubated using 5\% $\mathrm{CO}_{2}$ generating candle jar at $37^{\circ} \mathrm{C}$ for $24 \mathrm{~h}$. The plates were then examined for growth. Following the standard microbiological procedure, the bacterial isolates were characterized using colony morphology, hemolysis, gram stain, and by means of a panel of biochemical tests. In brief, for gram positive bacteria we used catalase, coagulase, optochin, bile solubility test and for gram negative isolates motility, indole, urea, lysine decarboxylase (LDC), oxidase, triple sugar iron agar (TSI) and citrate utilization tests were performed $[9,22]$.

\section{Antimicrobial susceptibility testing (AST)}

The Kary-Baur disc diffusion method was used for AST on Muller Hinton agar (MHA) (Oxoid, Ltd., England) as per the Clinical Laboratory Standards Institute (CLSI) guideline. For S. pneumonia isolates 5\% sheep blood was added on MHA and for those $H$. infleunzae Muller Hinton Chocolate agar was used. Morphologically identical 3 to 5 pure colonies from overnight cultured specimen were suspended in $5 \mathrm{ml}$ sterile nutrient broth (Oxoid, Ltd.,England) and mixed thoroughly to make the suspension homogenous. The inoculum turbidity was adjusted to 0.5 McFarland standards [22]. Then, the bacterial suspensions were seeded on the surface of the MHA using a sterile cotton swab and allowed to dry for about 3 to $15 \mathrm{~min}$. The antimicrobial impregnated disks were placed on the media using sterile forceps in such a way that each disk was placed at least $24 \mathrm{~mm}$ away from each other to avoid overlapping of zone of inhibition.
After the disk was placed on the inoculated media, the plate was allowed to stand for $15 \mathrm{~min}$, so that the antibiotic diffused into the media. The plates were incubated at $37^{\circ} \mathrm{C}$ for $24 \mathrm{~h}$ and the zone of inhibition was measured and interpreted as sensitive, intermediate and resistant as per the CLSI protocol $[22,23]$.

Based on the CLSI guideline, we used Ceftriaxone (CRO, $30 \mu \mathrm{g})$, Ciprofloxacin (CIP, $5 \mu \mathrm{g})$, Tetracycline (TE, $30 \mu \mathrm{g})$, Chloramphenicol $(\mathrm{C}, 30 \mu \mathrm{g})$, Erythromycin $(\mathrm{E}, 15 \mu \mathrm{g})$, Doxycycline (DO, $30 \mu \mathrm{g})$, Penicillin (P, $10 \mu \mathrm{g})$, Trimethoprim-sulfamethoxazole (TMP-SMX, $1.25+$ $23.75 \mu \mathrm{g}$ ), Oxacillin (OXA, $1 \mu \mathrm{g}$ ) and Clindamycin (DA, $2 \mu \mathrm{g}$ ) for gram positive isolates. Whereas, for gram negatives, we used Gentamycin $(\mathrm{CN}, 10 \mu \mathrm{g})$, Ampicillin (AMP, $10 \mu \mathrm{g})$, Amoxacilin-Clavunic acid $(20 / 10 \mu \mathrm{g})$, Trimethoprim-sulfamethoxazole (TMP-SMX, $1.25+$ $23.75 \mu \mathrm{g})$, Ceftriaxone (CRO, $30 \mu \mathrm{g})$, Doxycycline (DO, $30 \mu \mathrm{g})$, Tetracycline (TE, $30 \mu \mathrm{g}$ ), Ciprofloxacin (CIP, $5 \mu \mathrm{g})$, and Chloramphenicol (C, $30 \mu \mathrm{g})$. In addition to these, Piperacilin (PIP, $100 \mu \mathrm{g}$ ) and Ceftazidime (CAZ, $30 \mu \mathrm{g}$ ) were used for $P$. aeruginosa [23]. All antibiotics were obtained from Abtek Biologicals Ltd., UK.

\section{Quality control}

We strictly followed the manufacturers' instruction and bacteriological standard procedures during culture media preparation and AST testing. The standard reference bacteria strains such as $S$. aureus (ATCC ${ }^{\circ} 25,923$ ), $H$. influenzae (ATCC 49,247) and S. pneumoniae (ATCC $^{\bullet} 49,619$ ) were used as a quality control. Moreover, the whole procedure and result interpretation was cross-checked by a senior medical microbiologists working at APHI.

\section{Data organization, processing and analysis}

All data were entered, cleared, and analyzed using the SPSS statistical software package, Version 23.0 (IBM Corp. Released 2011. IBM SPSS Statistics for Windows. Armonk, NY: IBM Corp.). Descriptive data analysis was used to visualize differences with in the data. Frequencies, odd ratio (OR) with its $95 \%$ confidence interval (CI) were calculated. All covariates that were associated with the outcome variable in the bivariate analysis were subsequently included in the multivariable analysis to determine factors associated with culture positive sputum. A $P$ value less than or equal to 0.05 was considered to show statistically significant differences.

\section{Results}

\section{Demographic characteristics}

A total of 414 CAP suspected adult patients were enrolled in the study. Among these, 239 (57.7\%) were males and 191(46.1\%) were in the age group of 36-49 years with mean age of the participants at 42.4 years 
(standard deviation \pm 13.8 ). Moreover, $10(2.4 \%)$ of the participants had asthma and $12(2.9 \%)$ of them were smokers. The demographic characteristic of the study participants is summarized in Table 1.

Distribution of the bacterial growth and types of the isolates The overall prevalence of culture positive sputum was at 167 (40.3, 95\% CI; 35.5-44.9). The distribution of the isolates is summarized in Fig. 1. The most frequently identified bacteria was S. pneumoniae at 60 (35.9\%) followed by K. pneumoniae at 30 (18\%), S. aureus at 24 (14.4\%), P. aeruginosa at 19 (11.4\%) and $H$. influenzae at $14(8.4 \%)$. In this study, gram positive and gram negative isolates constituted $84(50.3 \%)$ and $83(49.7 \%)$, respectively.

\section{Antimicrobial resistance profile of the isolates}

The overall AMR profile of the isolates is presented in Table 2. In the present study $S$. pneumoniae showed

Table 1 Socio-demographic characteristics of the study participants at FHRH, 2018

\begin{tabular}{|c|c|c|}
\hline Variables & & Frequency (\%) \\
\hline \multirow[t]{2}{*}{ Sex } & Male & $239(57.7)$ \\
\hline & Female & $175(42.3)$ \\
\hline \multirow[t]{4}{*}{ Age in years } & $18-35$ & $91(22)$ \\
\hline & $36-49$ & $191(46.1)$ \\
\hline & $50-64$ & $98(23.7)$ \\
\hline & $\geq 65$ & $34(8.2)$ \\
\hline \multirow[t]{2}{*}{ Residence } & Rural & $256(61.8)$ \\
\hline & Urban & $158(38.2)$ \\
\hline \multirow[t]{6}{*}{ Occupation } & Government Employee & $65(15.7)$ \\
\hline & Farmer & $208(50.2)$ \\
\hline & Merchant & $46(11.1)$ \\
\hline & House wife & $50(12.1)$ \\
\hline & Daily laborer & $21(5.1)$ \\
\hline & Student & $24(5.8)$ \\
\hline \multirow[t]{4}{*}{ Educational Status } & No education & $249(60.1)$ \\
\hline & 1-8 Grade & $82(19.8)$ \\
\hline & 9-12 Grade & $60(14.5)$ \\
\hline & Diploma and above & $23(5.6)$ \\
\hline \multirow[t]{2}{*}{ Alcohol use } & Yes & $168(40.6)$ \\
\hline & No & $246(59.4)$ \\
\hline \multirow[t]{2}{*}{ Smoking } & Yes & $12(2.9)$ \\
\hline & No & $402(97.1)$ \\
\hline \multirow[t]{2}{*}{ Asthmatic case } & Yes & $10(2.4)$ \\
\hline & No & $404(97.60$ \\
\hline \multirow[t]{2}{*}{ Crowded living condition } & Yes & $198(47.8)$ \\
\hline & No & $216(52.2)$ \\
\hline
\end{tabular}

higher level of resistance to Oxacillin at (56.7\%) and Tetracyclin at (45\%). However, (96.7\%) of the S. pneumoniae were found sensitive to Chloroamphenicol. Similarly (96.7\%) of the S. pneumoniae isolates were found sensitive to Erythromycin and all of the S. pneumoniae were found sensitive to Ceftriaxone. Moreover, our study showed that (96.7\%) of the K. pneumoniae isolates were resistant to Amoxacilin-Clavunic acid. Further, (90\%) of the $K$. pneumoniae isolates were found resistant to Trimethoprim-Sulfamethoxazole and all of the K. pneumoniae isolates were resistant to Tetracycline and Ampicillin. However, (96.7\%) and (100\%) of these isolates were found sensitive to Ciprofloxacilin and Ceftriaxone, respectively.

Interestingly, in this study 127 (76\%) of the isolates showed resistance to three and more classes of antimicrobials; (Multi-drug Resistant). Specifically, 33 (55\%) of S. pneumoniae, 30(100\%) of K.pneumoniae, 24(100\%) of S. auerus, $8(42.1 \%)$ of $P$. aeruginosa, $14(100 \%)$ of $H$. influenzae, 9 (90\%) of E.coli, 5 (83.3\%) of P. mirabilis and $4(100 \%)$ of $P$. vulgaris isolates were found MDR (Table 3).

\section{Factors associated with culture positive sputum}

The multivariable analysis showed that overcrowded living condition [AOR 1.579 (95\%CI: 1.015-2.456)] and alcohol use [AOR 4.043 (95\% CI: 2.537-6.443)] were significantly associated with sputum culture positive result (Table 4).

\section{Discussion}

In our study the overall prevalence of culture positive sputum among adults was at $40.3 \%$. Studies conducted in Ethiopia and elsewhere in Africa and Europe have reported the prevalence of culture positive sputum among CAP suspected patients varied between 42 and $47.2 \%[9,10,15,24,25]$. The design of the studies including sample size and study subjects as well as the geographical variances might contribute for the difference of the results.

In the present study the predominant isolate was $S$. pneumoniae at 60 (35.8\%) followed by $K$. pneumonia at $30(18 \%)$ and S. aureus at $24(14.4 \%)$. This result is inconsistent with other studies conducted in Ethiopia and others with different geographical regions of the world $[1,10,25,26]$. A study in Jimma, Ethiopia for example reported lower proportion of $S$. pneumoniae isolates at (28.3\%) [9]. Similarly, our finding was significantly higher compared to a study reported in India at (3.4\%) [26], Iran at (25.8\%) [24], Estonia at (28.1\%). However, other studies done in China and other countries reported higher proportion of $S$. pneumoniae ranging from 36.4 to $66 \%[1,27,28]$. Likewise, in the present study, $K$. pneumoniae and S. aureus were the second and the third 


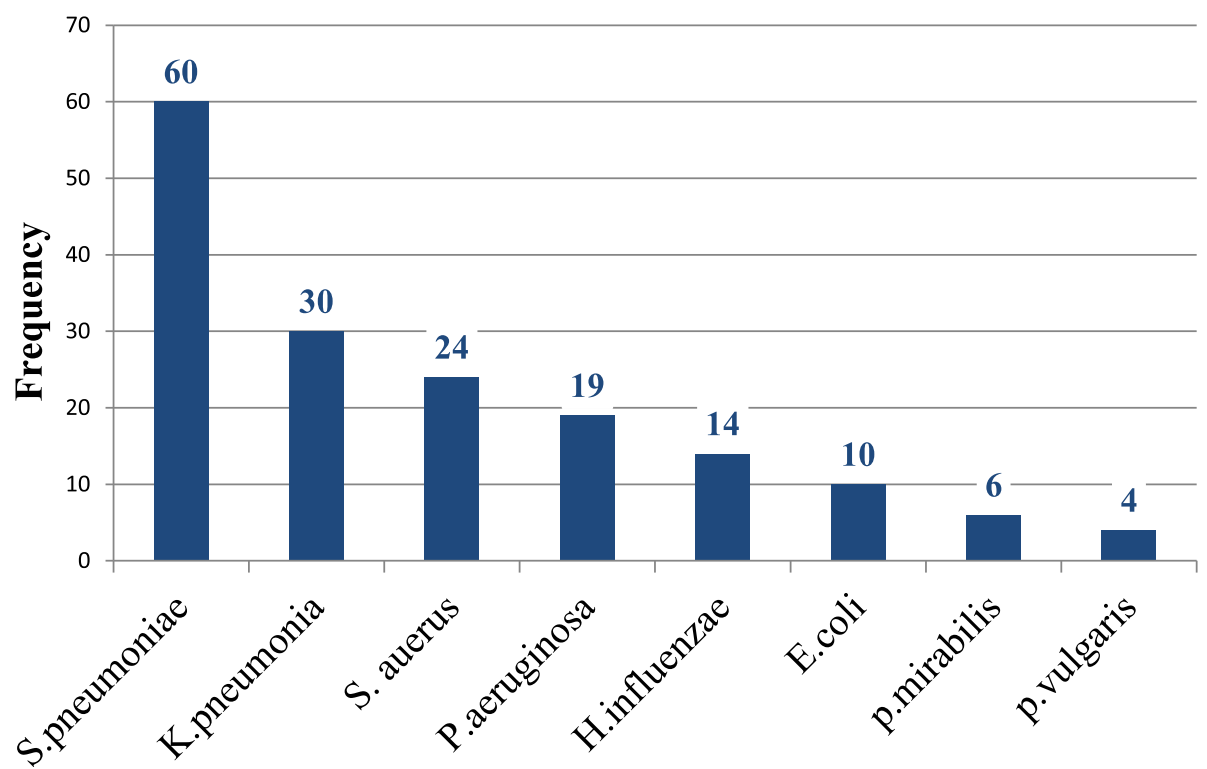

Fig. 1 The distribution of bacterial isolates identified from the participants at FHRH, 2018

most frequently identified isolates that accounted 18 and $14.4 \%$, respectively. Comparable findings have been reported by previous studies done in Ethiopia and abroad like Nigeria, China and India [1, 9, 10, 15, 24-26, 28].

In this study, we noted that $84(50.3 \%)$ of the isolates were gram positives while $83(49.7 \%)$ constitute the gram negatives. A study conducted in Ethiopia reported gram positive bacteria at $52.1 \%$ and gram negative isolates at $47.9 \%$ [10] from similar study participants.
Equally, a study in Ghana reported comparable proportion at $40 \%$ gram positive and $58 \%$ gram negatives isolates [29]. The varying proportion of isolates among these studies might be attributed due to the variation in the geographical distribution of the isolates, sample size and the specific methodological issues.

In this study, S. pneumoniae was the most common isolate at $56.7 \%$ found to be resistance to Oxacillin. However, $96.7 \%$ of these isolates were found susceptible

Table 2 Antimicrobial resistance profile of the isolated organisms at $\mathrm{FHRH}, 2018$

\begin{tabular}{|c|c|c|c|c|c|c|c|c|}
\hline \multirow[t]{2}{*}{ Antimicrobialtested } & \multicolumn{8}{|l|}{ Bacterial isolates $(\mathrm{N})$} \\
\hline & S.pneumoniae (60) & K.pneumoniae (30) & S. auerus(24) & P.aeruginosa (19) & H.influenzae (14) & E.coli (10) & P.mirabilis (6) & P.vulgaris(4) \\
\hline$N(\%) E$ & $2(3.3)$ & NA & $11(45.8)$ & NA & NA & NA & NA & NA \\
\hline$P$ & NA & NA & $18(75)$ & NA & NA & NA & NA & NA \\
\hline OXA & $34(56.7)$ & NA & $18(75)$ & NA & NA & NA & NA & NA \\
\hline TMP-STX & $5(8.3)$ & $27(90)$ & $21(87.5)$ & NA & $13(92.9)$ & $8(80)$ & $5(83.3)$ & $4(100)$ \\
\hline $\mathrm{CRO}$ & $0(0)$ & $0(0)$ & NA & $5(26.3)$ & $4(28.6)$ & $0(0)$ & $3(50)$ & $1(25)$ \\
\hline DA & $5(8.3)$ & NA & $2(8.3)$ & NA & NA & NA & NA & NA \\
\hline DO & 23(38.3) & $6(20)$ & 10(41.7) & NA & NA & $9(90)$ & $5(83.3)$ & $4(100)$ \\
\hline TE & $27(45)$ & $30(100)$ & 22(91.7) & NA & $14(100)$ & $9(90)$ & $6(100)$ & $4(100)$ \\
\hline AMP & NA & $30(100)$ & NA & NA & $6(42.9)$ & $7(70)$ & $5(83.3)$ & $4(100)$ \\
\hline $\mathrm{CN}$ & NA & $2(6.7)$ & NA & $11(57.9)$ & NA & $2(20)$ & $5(83.3)$ & $4(100)$ \\
\hline AMC & NA & 29(96.7) & NA & NA & $0(0)$ & $8(80)$ & $0(0)$ & (0) \\
\hline PIP & NA & NA & NA & $3(15.8)$ & NA & NA & NA & NA \\
\hline CIP & NA & $1(3.3)$ & $7(29.2)$ & $4(21.1)$ & $5(35.7)$ & $0(0)$ & $4(66.7)$ & $1(25)$ \\
\hline$C A Z$ & NA & NA & NA & $1(5.3)$ & NA & NA & NA & NA \\
\hline C & $2(3.3)$ & $6(20)$ & $7(29.2)$ & NA & $5(35.7)$ & $9(90)$ & $5(83.3)$ & $4(100)$ \\
\hline
\end{tabular}


Table 3 Multi-drug resistance (MDR) profile of the isolates at FHRH, 2018

\begin{tabular}{|c|c|c|c|c|c|c|c|c|c|c|}
\hline \multirow[t]{2}{*}{ Bacteria isolated } & \multicolumn{9}{|c|}{ Degree of resistance } & \multirow{2}{*}{$\begin{array}{l}\text { Total MDR } \\
\text { isolates } \geq \mathrm{R} 3\end{array}$} \\
\hline & Ro (\%) & R1 (\%) & R2 (\%) & R3 (\%) & R4 (\%) & R5 (\%) & R6 (\%) & R7 (\%) & R8 (\%) & \\
\hline S.pneumoniae $(n=60)$ & $2(3.3)$ & $25(41.7)$ & - & $8(13.3)$ & $22(36.7)$ & - & $3(5)$ & - & - & $33(55)$ \\
\hline K.pneumoniae $(n=30)$ & - & - & - & - & $1(3.3)$ & $22(73.3)$ & $7(23.3)$ & - & - & $30(100)$ \\
\hline S.aureus $(n=24)$ & - & - & - & $2(8.3)$ & $10(41.7)$ & $7(29.2)$ & $5(20.8)$ & - & - & $24(100)$ \\
\hline P.aeruginosa $(n=19)$ & - & $6(31.6)$ & $5(26.3)$ & $5(26.3)$ & $2(10.5)$ & $1(5.3)$ & - & - & - & $8(42.1)$ \\
\hline H.infleuenzae $(n=14)$ & - & - & - & $8(57.1)$ & - & $1(7.1)$ & $2(14.3)$ & $3(21.4)$ & - & $14(100)$ \\
\hline E.coli $(n=10)$ & - & $1(10)$ & - & $1(10)$ & $1(10)$ & - & $5(50)$ & $2(20)$ & - & $9(90)$ \\
\hline P.mirabilis $(n=6)$ & - & - & $1(16.7)$ & - & - & - & - & $2(33.3)$ & $3(50)$ & $5(83.5)$ \\
\hline P.vulgaris $(n=4)$ & - & - & - & - & - & - & - & $3(75)$ & $1(25)$ & $4(100)$ \\
\hline Total $(n=167)$ & $2(1.2)$ & $32(19.2)$ & $6(3.5)$ & $24(14.4)$ & $36(21.5)$ & $31(18.6)$ & $22(13.2)$ & $10(6)$ & $4(2.4)$ & $127(76)$ \\
\hline
\end{tabular}

Note: R0: susceptible to all antibiotics, R1-R8: resistance to 1, 2, 3, 4, 5, 6, 7 \& 8 antibiotics, $\geq$ R3: resistance to 3 or more antibiotic, MDR: multidrug resistance

to Erythromycin. Previous studies conducted in Ethiopia and Europe had reported similar findings on this regard $[9,10,22]$. In this study we also noticed that K. pneumoniae showed $100 \%$ resistance to Tetracycline and $96.7 \%$ to Amoxacilin-Clavunic acid. This is in line with the studies conducted in Arbamich, Ethiopia [10], Nigeria [25] and Bangladesh [1]. In addition, in the present study we noted high level of antimicrobial resistance to Tetracycline, Ampicillin, and Trimethoprimsulfamethoxazole. This might be related with a high rate of prescription and self-medication of these drugs in the study area. On the other hand, most of the isolates in this study were susceptible for Ceftriaxone.

The overall prevalence of MDR was at $76 \%$ which is slightly higher as compared to the studies conducted in Jimma and Arbaminch, Ethiopia where the prevalence

Table 4 Factors associated with culture positive sputum at FHRH, 2018

\begin{tabular}{|c|c|c|c|c|c|c|c|}
\hline \multirow[t]{2}{*}{ Variables } & & \multicolumn{2}{|l|}{ Culture } & \multirow[b]{2}{*}{$\operatorname{COR}(95 \% \mathrm{Cl})$} & \multirow[b]{2}{*}{$p$-value } & \multirow[b]{2}{*}{$\mathrm{AOR}(95 \% \mathrm{Cl})$} & \multirow[b]{2}{*}{$p$-value } \\
\hline & & Positive & Negative & & & & \\
\hline \multirow[t]{2}{*}{ Sex } & Male & 100 & 139 & $1.160(0.778,1.728)$ & 0.466 & & \\
\hline & Female & 67 & 108 & & & & \\
\hline \multirow[t]{4}{*}{ Age } & $18-35$ & 35 & 54 & & & & \\
\hline & $36-49$ & 85 & 108 & $1.199(0.722,1.994)$ & 0.483 & & \\
\hline & $50-64$ & 32 & 66 & $0.741(0.408,1.344)$ & 0.323 & & \\
\hline & $\geq 65$ & 15 & 19 & $1.206(0.544,2.676)$ & 0.645 & & \\
\hline \multirow[t]{6}{*}{ Occupation } & Government employee & 31 & 34 & & & & \\
\hline & Farmer & 67 & 141 & $0.521(0.296,0.919)$ & 0.024 & $0.390(0.105,1.450)$ & 0.160 \\
\hline & Merchant & 25 & 21 & $1.306(0.612,2.784)$ & .490 & & \\
\hline & House wife & 22 & 28 & $0.862(0.411,1.808)$ & 0.694 & & \\
\hline & Daily laborer & 15 & 6 & $2.742(0.946,7.950)$ & 0.063 & $1.796(0.481,6.709)$ & 0.384 \\
\hline & Student & 7 & 17 & $0.452(0.165,1.235)$ & 0.121 & $0.606(0.165,2.229)$ & 0.451 \\
\hline \multirow[t]{4}{*}{ Educational status } & No education & 88 & 161 & $1.025(0.418,2.512)$ & 0.957 & & \\
\hline & $1-8$ grade & 40 & 42 & $1.786(0.683,4.669)$ & 0.237 & & \\
\hline & 9-12 grade & 31 & 29 & $2.004(0.740,5.428)$ & 0.171 & $2.228(0.728,6.820)$ & 0.160 \\
\hline & Diploma and above & 8 & 15 & & & & \\
\hline \multirow[t]{2}{*}{ Residence } & Rural & 85 & 171 & $0.461(0.307,0.692)$ & 0.000 & $0.638(0.283,1.439)$ & 0.279 \\
\hline & Urban & 82 & 76 & & & & \\
\hline \multirow[t]{2}{*}{ Over Crowded living condition } & Yes & 94 & 104 & $1.771(1.191,2.632)$ & 0.005 & $1.579(1.015,2.456)$ & 0.043 \\
\hline & No & 73 & 143 & & & & \\
\hline \multirow[t]{2}{*}{ Alcohol use } & Yes & 97 & 71 & $3.435(2.273,5.190)$ & 0.000 & $4.043(2.537,6.443)$ & 0.000 \\
\hline & No & 70 & 176 & & & & \\
\hline
\end{tabular}


was at $62.7 \%$ [9] and 60.3\% [10], respectively. MDR in resource constraint settings is highly contributed by the widespread misuse of antimicrobials by patients due to lack of access to appropriate treatment and under use of drugs due to inadequate dosing or incomplete treatment courses. The other factor contributed to MDR might be over use of drugs while the infectious pathogen is not well characterized due to the absence of well-organized bacteriology laboratory in the study area. In Ethiopia, it is very common to buy and use antimicrobials and other drugs from private pharmacies without prescription. These all could play a role in the increasing trend of antimicrobial resistance in the different health settings of Ethiopia in general and our study site in particular.

Our study measured factors associated to culture positive sputum among CAP suspected patients. The study results showed that overcrowded living condition [AOR 1.579 (95\%CI: 1.015-2.456)] and alcohol use [AOR 4.043 (95\% CI: 2.537-6.443)] were found significantly associated. Similar couple of studies done in Europe reported that risk for culture positive sputum was increased among individuals who have been consuming alcohol and living in a household of over 10 people $[12,30]$ the latter may results in indoor air pollution. A recently published review paper also reported that alcohol consumption increased the risk of CAP [31]. There are numerous possible instruments to explain the observation that alcohol consumption increased the risk of CAP, including but not limited to the sedative properties of alcohol which can reduce oropharyngeal tone, leading to an increased risk of aspiration of pathogens from the upper respiratory tract. High levels of alcohol intake can also modify the alveolar macrophage function, hence diminishing pulmonary defense against infection [31]. A review by Almirall and his colleagues in 2017 indicated that age, smoking, environmental exposures, malnutrition, previous CAP, chronic bronchitis/chronic obstructive pulmonary disease, asthma, functional impairment, poor dental health, immunosuppressive therapy, oral steroids, and treatment with gastric acid-suppressive drugs were predictors of CAP [32].

This study has provided valuable data on the bacterial isolates and their drug resistance profile among CAP adult patients. Despite this strength, our study has some drawbacks as well; we did not attempt to isolate and identify some common pathogens like Chlamydia, Mycoplasma, Legionella species and serotyping was not also done to $H$. influenzae due to resource limitation. In addition, the molecular investigations for the isolated bacteria were not performed. The study also didn't provide data on serotyping of S. pneumonaie, characterizing of methicillin resistant $S$. aureus and extended-spectrum beta-lactamaze as well as carbapenemase-producing organisms detection and analysis.

\section{Conclusions}

In the studied area, relatively higher proportions of $S$. pneumoniae, K.pneumoniae and S.aureus were identified. Most of the isolates were found susceptible to Ceftriaxone. However, antimicrobial resistance including MDR was observed to a number of commonly used antibiotics, such as Trimethoprim-sulfamethoxazole, Ampicilin and Tetracyclin. Therefore, as there is no standardized surveillance at FHRH, periodic investigation of the etiologic agents and their antibiotic resistance profile should be made in order to guide clinicians in the management of CAP. Overcrowded living style and alcohol use were found predictors of culture positive sputum. So, interventions for reducing CAP should integrate lifestyle factors related to household and alcohol use. Additional, large scale studies should be considered to further characterize the pathogens involved in CAP.

\section{Abbreviations}

APHI: Amhara public health institute; AST: Antimicrobial susceptibility testing; ATCC: American type culture collection; BAP: Blood agar plate;

CAP: Community acquired pneumonia; CLSI: Clinical laboratory standard institute; FHRH: Felege hiwot referral hospital; LDC: Lysine decarboxylase agar; LIA: Lysine iron agar; MAC: MacConkey agar; MDR: Multi drug resistant; MHA: Muller hinton agar; MSA: Manitol salt agar; QC: Quality control; SIM: Simon indole motility; SPSS: Statistical package for social sciences; TSI: Triple sugar iron agar

\section{Acknowledgments}

Authors would like to thank the Amhara Public Health Institute and its staffs working at the microbiology department for their unreserved support. We also thank Felege Hiwot Referral Hospital lab staff members and nurses working in adult outpatient department for their support in the process of the data and specimen collection. Finally, our acknowledgment goes to the study participants

\section{Authors' contributions}

DT conceived the research idea. DT has also involved in the data collection and interpretation of the result. $\mathrm{FaB}$ and $\mathrm{FeB}$ has involved in interpretation of the result and evaluating the scientific content of the study. AD has involved in data analysis and rationalizing the method section and manuscript preparation. All authors read and approved the final manuscript for submission.

Funding

This study was partially funded by Bahir Dar University.

Availability of data and materials

Not applicable.

Ethics approval and consent to participate

Ethical clearance was obtained from Bahir Dar University, College of Medicine and Health Sciences Institutional Review Board. Informed written consent was obtained from the study participants after explaining the purpose and objective of the study. The laboratory result from the study participant was communicated to their physicians for appropriate management. All patient data were kept confidential.

Consent for publication

Not applicable in this section.

\section{Competing interests}

The authors declare that they have no competing interests.

Author details

${ }^{1}$ Amhara Public Health Institute (APHI), Bahir Dar, Ethiopia. ${ }^{2}$ Department of Medical Laboratory Sciences, College of Medicine and Health Sciences, Bahir 
Dar University, P.O.BOX: 1383, Bahir Dar, Ethiopia. ${ }^{3}$ Center for Innovative Drug development and Therapeutics Trials for Africa (CDT-Africa), Addis Ababa University, Addis Ababa, Ethiopia.

Received: 17 December 2018 Accepted: 10 June 2019

Published online: 14 June 2019

\section{References}

1. Akter S, Shamsuzzaman S, Jahan F. Community acquired bacterial pneumonia: aetiology, laboratory detection and antibiotic susceptibility pattern. Malays J Pathol. 2014;36:97-103.

2. Sligl WI, Marrie TJ. Severe community-acquired pneumonia. Crit Care Clin. 2013;29(3):563-601.

3. van Gageldonk-Lafeber A, et al. The aetiology of community-acquired pneumonia and implications for patient management. Neth J Med. 2013; 71(8):418-25.

4. Prina E, Ranzani OT, Torres A. Community-acquired pneumonia. Lancet. 2015;386(9998):1097-108

5. Khawaja A, et al. Etiology and outcome of severe community acquired pneumonia in immunocompetent adults. BMC Infect Dis. 2013;13(1):94.

6. Wiersinga, W., et al., Management of Community-Acquired Pneumonia in adults: 2016 guideline update from the Dutch working party on antibiotic policy (SWAB) and Dutch Association of Chest Physicians (NVALT). 2016.

7. Black A. Community-acquired pneumonia-a clinical approach to assessment and management: CPD. S Afr Fam Pract. 2008;50(3):15-23.

8. Bayisa $G$, et al. Clinical outcome and in-vitro microbiological response of bacterial isolates to commonly prescribed antibiotics among hospitalized patients with community acquired pneumonia in Jimma University specialized hospital, Ethiopia. Indian J Pharmacy Pract. 2015;8(4):183.

9. Regasa B, et al. Antimicrobial susceptibility pattern of bacterial isolates from community-acquired pneumonia patients in Jimma University specialized hospital, Jimma, Ethiopia. Saudi J Health Sci. 2015;4(1):59.

10. Regasa B. Drug resistance patterns of bacterial pathogens from adult patients with pneumonia in Arba Minch hospital, South Ethiopia. Glob J Med Res. 2014;14:5.

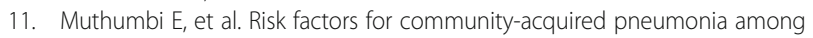
adults in Kenya: a case-control study. Pneumonia. 2017;9(1):17.

12. Torres A, et al. Risk factors for community-acquired pneumonia in adults in Europe: a literature review. Thorax. 2013;68(11):1057-65.

13. Mandell LA, et al. Infectious Diseases Society of America/American Thoracic Society consensus guidelines on the management of community-acquired pneumonia in adults. Clin Infect Dis. 2007:44(SUPPL. 2):S27-72.

14. Onyedum CC, Chukwuka J. Admission profile and management of community acquired pneumonia in Nigeria-5 year experience in a tertiary hospital. Respir Med. 2011;105(2):298-302.

15. Leesik $\mathrm{H}$, et al. Microbial pathogens of adult community-acquired pneumonia in southern Estonia. Medicina (Kaunas). 2006;42(5):384-94.

16. Prasad R. Community acquired pneumonia: clinical manifestations. J Assoc Physicians India. 2012;60:10-2.

17. Regasa B. Aetiology of bacterial pathogens from adult patients with community-acquired pneumonia in Arba Minch hospital, South Ethiopia. Science. 2014;3(3):33-6.

18. Peto $L$, et al. The bacterial aetiology of adult community-acquired pneumonia in Asia: a systematic review. Trans R Soc Trop Med Hyg. 2014; 108(6):326-37.

19. Almirall J, et al. New evidence of risk factors for community-acquired pneumonia: a population-based study. Eur Respir J. 2008;31(6):1274-84.

20. Magiorakos AP, et al. Multidrug-resistant, extensively drug-resistant and pandrug-resistant bacteria: an international expert proposal for interim standard definitions for acquired resistance. Clin Microbiol Infect. 2012;18(3): 268-81.

21. Naderi $\mathrm{H}$, et al. Etiological diagnosis of community-acquired pneumonia in adult patients: a prospective hospital-based study in Mashhad, Iran. Jundishapur J Microbiol. 2015;8(8).

22. Cheesbrough M. District laboratory practice in tropical countries. 2nd ed. Cambridge University Press; 2006.

23. Patel, J.B., Performance standards for antimicrobial susceptibility testing 2017 : Clinical and Laboratory Standards Institute.

24. Hashemi SH, et al. Bacterial aetiology and antimicrobial resistance of community-acquired pneumonia in the elderly and younger adults. Trop Dr. 2010;40(2):89-91.
25. Egbagbe ER. Mordi, Aetiology of lower respiratory tract infection in Benin City, Nigeria. J Med Biomed Res. 2006;5(2):22-7.

26. Shah BA, et al. Bacteriological and clinical profile of community acquired pneumonia in hospitalized patients. Lung India. 2010:27(2):54.

27. Johansson $\mathrm{N}$, et al. Etiology of community-acquired pneumonia: increased microbiological yield with new diagnostic methods. Clin Infect Dis. 2010; 50(2):202-9

28. Tao $L$, et al. Etiology and antimicrobial resistance of community-acquired pneumonia in adult patients in China. Chin Med J. 2012;125(17):2967-72.

29. Ammisah I, Pappoe F. Prevalence of bacterial pathogens isolated from sputum cultures of hospitalized adult patients with community-acquired pneumonia at the cape coast teaching hospital, Ghana. J Med Res. 2014; 3(5):58-61.

30. Rivero-Calle I, et al. Incidence and risk factor prevalence of communityacquired pneumonia in adults in primary care in Spain (NEUMO-ES-RISK project). BMC Infect Dis. 2016;16(1):645.

31. Simou E, Britton J, Leonardi-Bee J. Alcohol and the risk of pneumonia: a systematic review and meta-analysis. BMJ Open. 2018;8(8):e022344.

32. Almirall J, Serra-Prat M, Bolíbar I, Balasso V. Risk factors for communityacquired pneumonia in adults: a systematic review of observational studies. Respiration. 2017;94(3):299-311.

\section{Publisher's Note}

Springer Nature remains neutral with regard to jurisdictional claims in published maps and institutional affiliations.
Ready to submit your research? Choose BMC and benefit from:

- fast, convenient online submission

- thorough peer review by experienced researchers in your field

- rapid publication on acceptance

- support for research data, including large and complex data types

- gold Open Access which fosters wider collaboration and increased citations

- maximum visibility for your research: over $100 \mathrm{M}$ website views per year

At BMC, research is always in progress.

Learn more biomedcentral.com/submissions 